\title{
The Potential Protective Effect of Sesame Oil and Canola Oil on Rats Exposed to Malathion
}

Daklallah A. Almalki

Department of Biology, Faculty of Science and Arts (Qelwah), Albaha University, Saudi Arabia Received: 10 Sept. 2019/ Accepted 30 Oct. 2019/ Publication date: 10 Nov. 2019

\begin{abstract}
Currently, the environmental pollution is occurring on a vast and unprecedented scale around the globe. Pesticides are the largest group of chemicals that are used widely in modern agricultural practices. Pesticides have been associated with health and environmental issues, and the agricultural use of certain pesticides has been abandoned. Pesticides are basically poisons and therefore toxic to living organism at particular dose. Medicinal plants have a promising future because there are about half million plants around the world, and most of them their medical activities have not investigate yet, and their medical activities could be decisive in the treatment of present or future studies. Natural products from plants, animals and minerals are the basis for treating human diseases. The purpose of the present study was to evaluate the effects of sesame oil and canola oil on male rats exposed to malathion. Experimental rats were divided into six groups. Group 1 was served as normal control. Rats of group 2 were exposed to malathion. Rats of group 3 were treated with sesame oil and malathion. Rats of group 4 were subjected to canola oil and malathion. Rats of group 5 and 6 were supplemented with sesame oil and canola oil respectively. After the end of experimental duration (8 weeks), rats of group 2 showed significant reduction of body weight gain, and severe hematological and biochemical alterations including significant decreases of RBC, HB, Hct, WBC, total protein, glucose and CAT, and increases of ALT, AST, ALP, total bilirubin, triglycerides, cholesterol, creatinine, uric acid and MDA values. Administration of sesame oil and canola oil improved the observed hematological and biochemical alterations induced by malathion intoxication. These new findings indicate that sesame oil and canola oil represent protective roles on hematological and biochemical disturbances induced by malathion toxicity due to their antioxidant activities.
\end{abstract}

Keywords: Malathion, Sesame oil, Canola oil, Antioxidant, Blood, Rats

\section{Introduction}

Environmental pollution is the contamination of the ecosystem that causes harm or discomfort to the physical systems or living organisms. The increase in pollution is a global problem, due to the use of toxic chemical substances or by synthetic compounds such as pesticides. Humans whose position in the food chain is at the top were exposed to various types of environmental contaminants at different stages of life, majority of which are harmful. An increasing number of natural and manmade pollutants have pervaded the environment in the last few decades, which ultimately affect the health and well being living organisms. Health risks due to pesticides toxicity are one of the world's current problems. Environmental pollutants are believed to be factors adversely affecting animal and human organisms (Mamane et al., 2015; Lushchak et al., 2018). Pesticides are widely utilized chemicals in agriculture, intended to preserve the productivity of crops and the quality of harvests. The universal use of assorted groups of pesticides causes global environmental pollution, as well as the accidental exposure of humans to these pesticides (Kapka-Skrzypczak et al., 2011). Exposure to pesticides may be a major cause of various disorders in humans and animals (Hariri et al., 2018; Paul et al., 2018). Malathion is one of the most widely used organophosphorus insecticides throughout the world. Malathion is used mostly in agriculture and in public health programs to control infestations of insects. It is also used as pest control for agricultural food and feed crops (U.S. EPA, 2006). Malaoxon, the oxon generated from malathion, is more toxic than malathion and is formed by the oxidation of malathion and may also be present as an impurity in the parent compound. Structurally, malathion has similarities with naturally occurring compounds, and their primary target of action in insects is the nervous system (Taylor, 1990; Klaasen, 1990). One of the main toxic effects of malathion on the central nervous system is related to the inhibition of acetylcholinesterase (AChE)

\section{Corresponding Author: Dr. Daklallah A. Almalki, Department of Biology, Faculty of Science and Arts} (Qelwah), Albaha University, Saudi Arabia. Email: Daklalmalki7@gmail.com 
activity, which produces acute hypercholinergic syndrome (Kwong, 2002). Moreover, previous experimental investigations showed that malathion induced various biochemical and histological changes in experimental animals (Baiomy et al., 2015; Abdel-Salam et al., 2018; Gupta et al., 2019; Hosseini et al., 2019).

Nowadays, a lot of research has been conducted on the use of plants products as natural remedies because of their fewer side effects, easy and cheap availability. The therapeutic use of plants and their extracts may be a promising approach for the treatment of different diseases. The use of herbal medicines for health prevention and ailments is an increasing trend worldwide (Kennedy et al., 2016). Sesame oil is the extract of the plant, Sesamum indicum, Pedaliaceae family. Sesame oil has phenolic compounds, non-protein amino acids, alkaloids, cacogenics glycosides, polyunsaturated fats and lipids, mucilage, phospholipids, thiazole, disulphide, ketones, aldehyde, vitamins as B1, B2, C and $\mathrm{E}$ and trace elements such as calcium, magnesium, iron, copper, zinc and phosphorus (Konan et al., 2008; Shittu et al., 2009). Sesamin and sesaminol are the major phenolic constituents of sesame oil with broad spectrum pharmacological effects including antimutagenic, antioxidant, antihypertensive, anti-inflammatory, and antithrombotic (Sankar et al., 2005). Canola (Brassica napus), Brassicaceae family, is one of the top five oilseed crops cultivated worldwide and the major oilseed crop in Canada. It contains almost 2:1 ratio of $\mathrm{n} 6$ to $\mathrm{n} 3$ fatty acids which has been reported to be preferred from the health point of view as well as high content of vitamin E. Canola seed is much richer in phenolic compounds than any other oilseed (Ackman, 1994; Rice, 1944; Naczk et al., 1998). Additionally, the seeds contain bioactive compounds including antioxidant vitamins such as tocopherol (mainly alpha tocopherol), phenolic molecules (canolol, sinapic acid, sinapine), coenzyme $\mathrm{Q}(\mathrm{CoQ})$ and phytosterols. These micronutrients have healthy metabolic, anti-inflammatory and physiologic effects (Xu et al., 2014). Recently, there are no experimental investigations on the effect of sesame oil and canola oil on malathion toxicity. Therefore, The main objective of this study was to investigate malathion impact on blood parameters and to examine the ability of sesame oil and canola oil to combat malathion toxicity in albino male rats. The findings could be useful to understand malathion toxicity and useful protection.

\section{Material and Methods}

\section{Animals and experimental design}

The experiments were done using male albino rats of Wistar strain, weighing 205-223 g. The animals were maintained in controlled temperature $\left(20 \pm 1^{\circ} \mathrm{C}\right)$, humidity $(65 \%)$ and a 12 -hour darklight cycle, with balanced food and free access to water. Experimental rats were randomly divided into six equal groups ( $\mathrm{n}=10$ each). Group 1 was untreated and served as normal control. Rats of group 2 were orally treated with malathion at a dose of $150 \mathrm{mg} / \mathrm{kg}$ body weight, BW, five times weekly for a period of eight weeks. Rats of group 3 were orally supplemented with sesame oil at a dose of 800 $\mathrm{mg} / \mathrm{kg} \mathrm{BW}$ and after three hours treated with malathion at the same dose given to group 2. Rats of group 4 were orally treated with canola oil at a dose of $800 \mathrm{mg} / \mathrm{kg} \mathrm{BW}$ and after three hours received malathion at the same dose given to group 2 . Rats of group 5 were orally supplemented with sesame oil at the same dose given to group 3. Rats of group 6 were orally supplemented with canola oil at the same dose given to group 4.

\section{Body weight changes}

Body weight changes of all rats were measured at the start of the experimental duration and after eight weeks using a digital balance. The experimental rats were observed for signs of abnormalities throughout the period of study.

\section{Blood sampling and analysis}

After eight weeks, animals were fasted for 8 hours, water was not restricted, and then anaesthetized with diethyl ether. Blood samples were collected from orbital venous plexus in heparinized tubes and non-heparinized tubes. Blood samples in heparinized tubes were used to estimate the values of red blood corpuscles count (RBC), hemoglobin $(\mathrm{Hb})$, hematocrit (Hct) and white blood corpuscles count (WBC) using auto hematology analyzer (BC-2800 vet.). Blood samples in non-heparinized tubes were centrifuged at $2000 \mathrm{rpm}$ for 20 minutes to obtain serum. Serum levels 
of alanine aminotransferase (ALT), aspartate aminotransferase (AST), alkaline phosphatase (ALP), total bilirubin, total protein, glucose, triglycerides, cholesterol, creatinine and uric acid were evaluated using Dimension Vista ${ }^{\circledR} 1500$ System, USA. The levels of serum malondialdehyde (MDA) and catalase (CAT) were estimated using the methods of Ohkawa et al. (1979) and Aebi (1984) respectively.

\section{Statistical analysis}

Data are reported as the mean \pm standard deviation (SD). Differences between means were evaluated by one-way analysis of variance (ANOVA). Statistical analysis was performed using Statistical Package for Social Sciences (SPSS) for Windows version 22.0 software. The level of significance was set at $P<0.05$.

\section{Results}

The body weights after eight weeks of all experimental groups are represented in Fig. 1. Gradual increases in the body weight gain of normal control rats $(55.2 \%)$ and those supplemented with sesame oil (55.7\%) and canola oil (52.3\%) compared with their initial body weights. Moreover, Significant increases of body weight gain were observed in rats treated with sesame oil plus malathion $(50.3 \%)$ and canola oil plus malathion $(50.4 \%)$. The minimum body weight gain was noted in rats treated with only malathion $(36.2 \%)$.

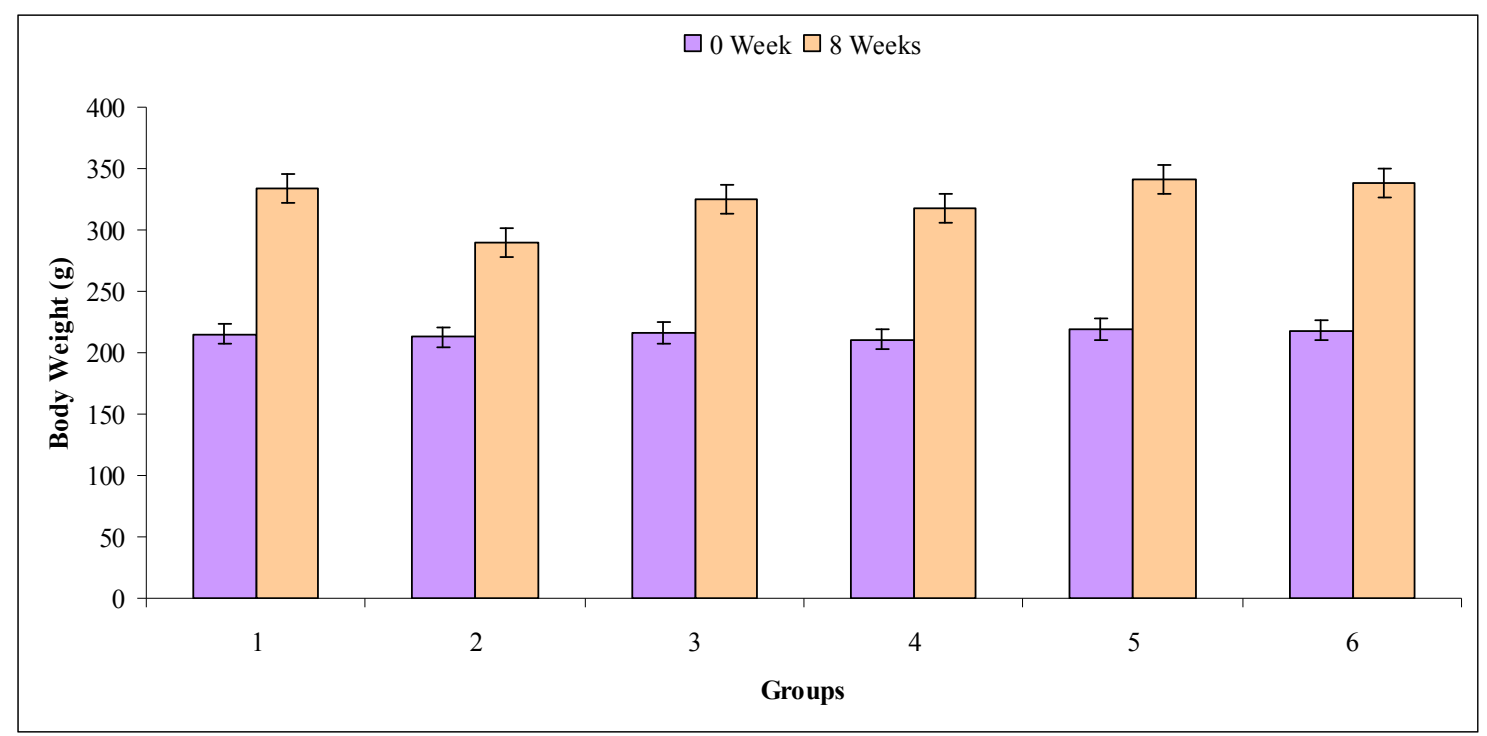

Fig. 1: Changes of body weight after eight weeks in control (group 1), malathion (group 2), sesame oil plus malathion (group 3), canola oil plus malathion (group 4), sesame oil (group 5) and canola oil (group 6) treated rats.

Figures 2-5 demonstrate the values of RBC (Fig. 2), Hb (Fig. 3), Hct (Fig, 4) and WBC (Fig. 5) in all experimental groups. Statistically decreases in the value of RBC $(P<0.000), \mathrm{Hb}(\mathrm{P}<0.000)$, Hct $(P$ $<0.000)$ and WBC $(P<0.000)$ in rats treated with malathion (group 2). Likewise, rats of group 4 showed significant decreases in the value of RBC $(P<0.001)$, Hb $(P<0.05)$, Hct $(P<0.05)$ and WBC $(P<0.001)$. In rats of group 3 , the value of WBC was statistically declined $(P<0.05)$, while the values of $\mathrm{RBC}, \mathrm{Hb}$ and $\mathrm{Hct}$ were notably unchanged. Additionally, no statistically significant difference was observed in the values of $\mathrm{RBC}, \mathrm{Hb}$, Hct and WBC normal rats supplemented with sesame oil (group 5) and canola oil (group 6) compared with normal control rats (group 1).

The levels of serum ALT, AST, ALP and total bilirubin are shown in Table 1. The levels of serum ALT were significantly elevated in rats treated malathion $(P<0.000)$, sesame oil plus malathion $(P<0.05)$ and canola oil plus malathion $(P<0.000)$. The levels of serum AST were markedly raised in rats exposed malathion $(P<0.000)$, sesame oil plus malathion $(\mathrm{P}<0.05)$ and canola oil plus malathion $(P<0.001)$. Furthermore, statistically increases in the level of serum ALP 
were noted in rats treated with malathion $(P<0.000)$, sesame oil plus malathion $(P<0.05)$ and canola oil plus malathion $(P<0.001)$. Serum total bilirubin level was statistically enhanced in rats treated with malathion $(P<0.000)$, sesame oil plus malathion $(P<0.05)$ and canola oil plus malathion $(P<$ 0.05). Insignificant alterations of serum ALT, AST, ALP and total bilirubin levels were noted in sesame oil (group 5) and canola oil (group 6) treated rats as compared with normal control rats of group 1 .

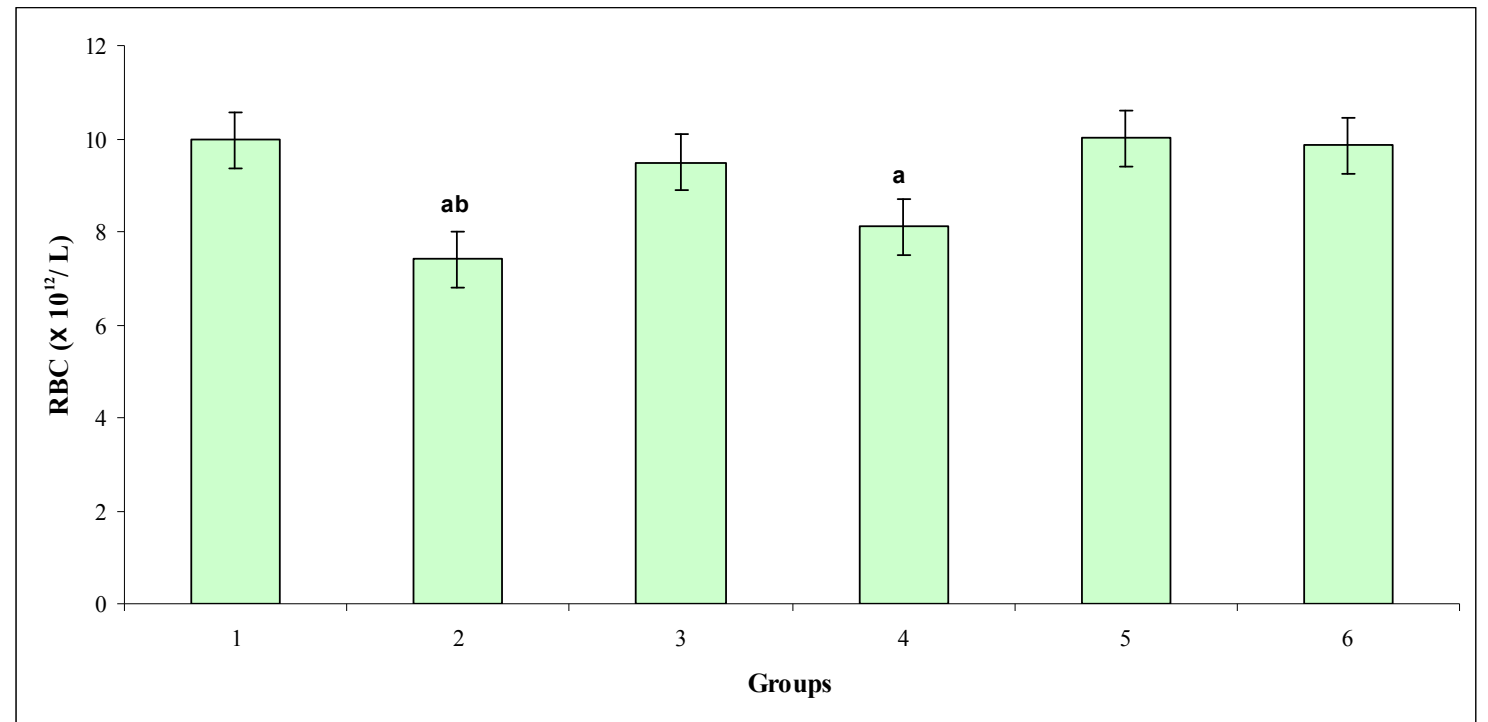

Fig. 2: The value of RBC after eight weeks in control (group 1), malathion (group 2), sesame oil plus malathion (group 3), canola oil plus malathion (group 4), sesame oil (group 5) and canola oil (group 6) treated rats. Data are shown as means \pm SD of 8 animals per group. ${ }^{\text {a Mean value }}$ was significantly different from that of normal control rats. ${ }^{b}$ Mean value was significantly different between group 2 and groups 3, 4, 5 and 6 .

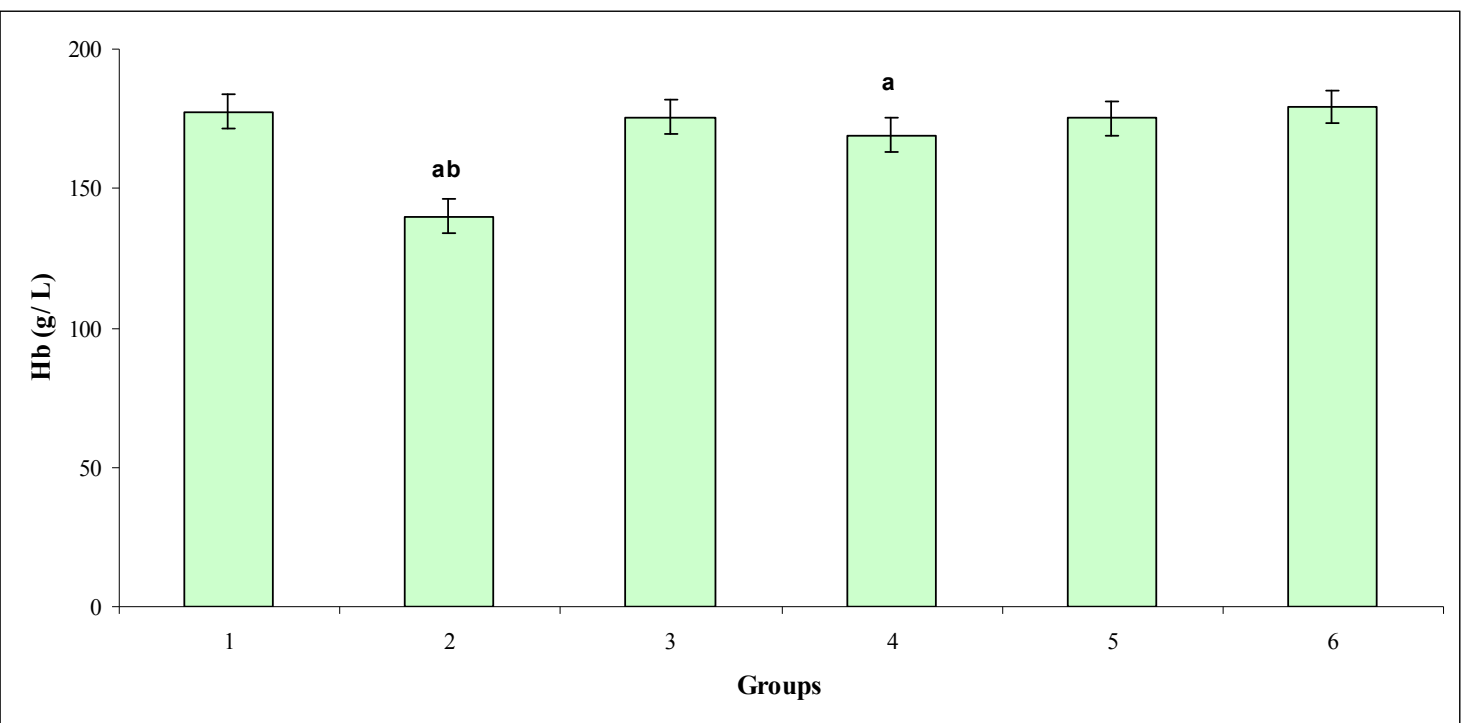

Fig. 3: The value of $\mathrm{Hb}$ after eight weeks in control (group 1), malathion (group 2), sesame oil plus malathion (group 3), canola oil plus malathion (group 4), sesame oil (group 5) and canola oil (group 6) treated rats. Data are shown as means \pm SD of 8 animals per group. ${ }^{a}$ Mean value was significantly different from that of normal control rats. ${ }^{b}$ Mean value was significantly different between group 2 and groups 3, 4, 5 and 6. 


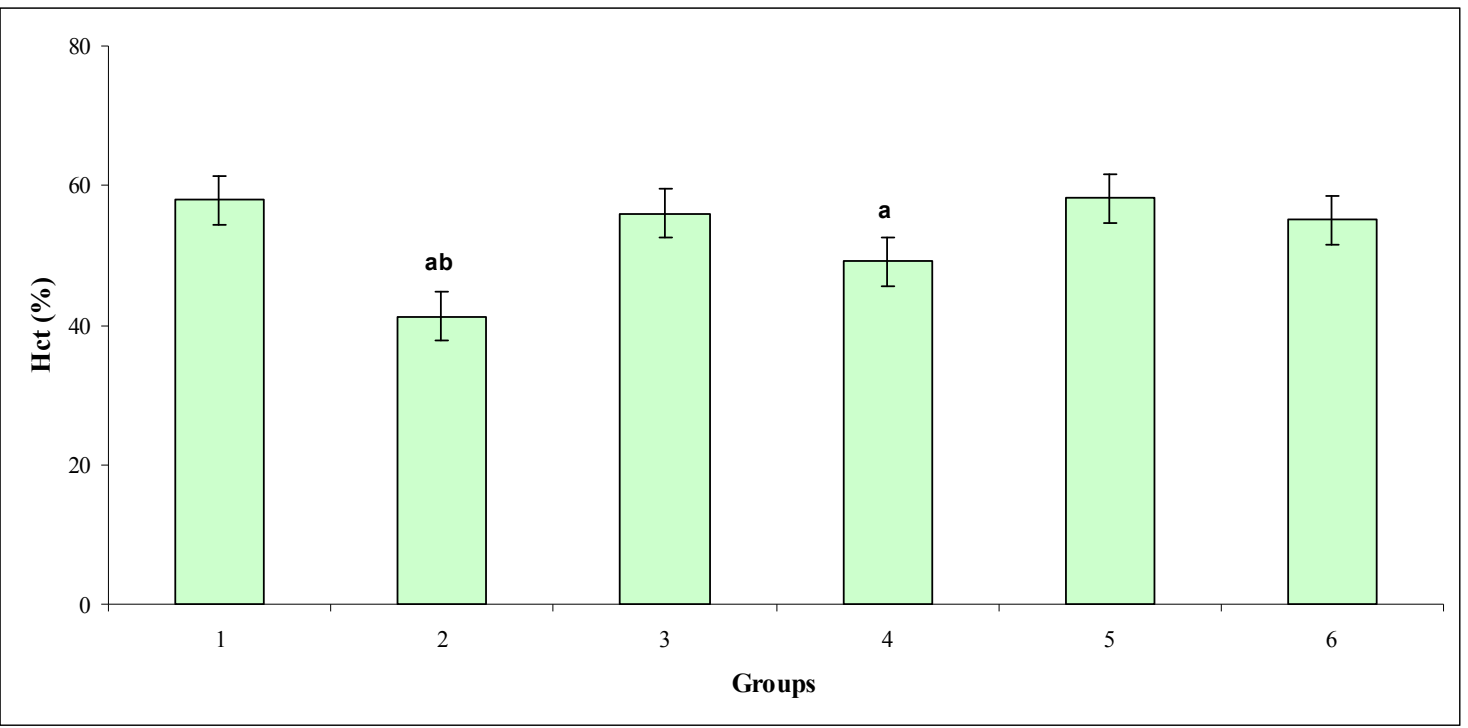

Fig. 4: The value of Hct after eight weeks in control (group 1), malathion (group 2), sesame oil plus malathion (group 3), canola oil plus malathion (group 4), sesame oil (group 5) and canola oil (group 6) treated rats. Data are shown as means $\pm \mathrm{SD}$ of 8 animals per group. ${ }^{\mathrm{a}}$ Mean value was significantly different from that of normal control rats. ${ }^{b}$ Mean value was significantly different between group 2 and groups 3, 4, 5 and 6.

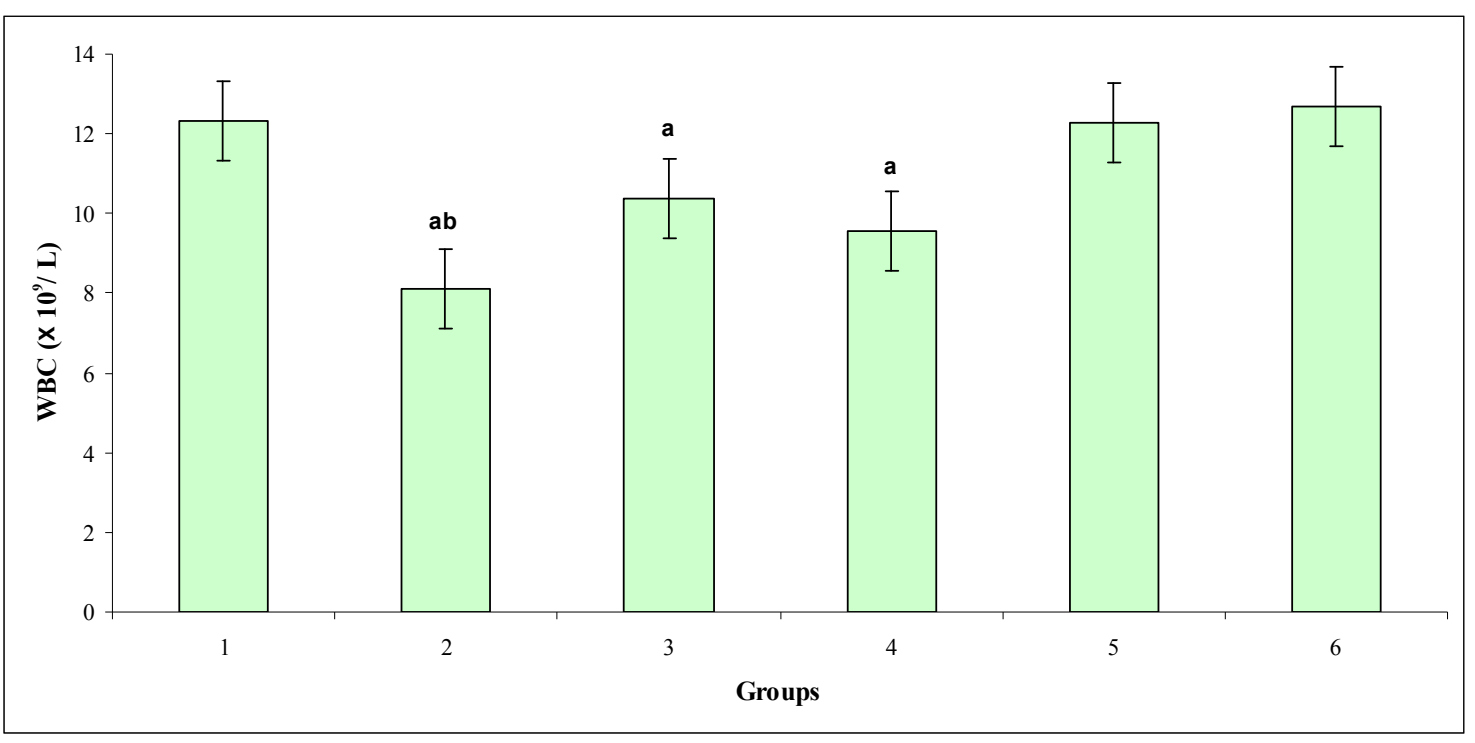

Fig. 5: The value of WBC after eight weeks in control (group 1), malathion (group 2), sesame oil plus malathion (group 3), canola oil plus malathion (group 4), sesame oil (group 5) and canola oil (group 6) treated rats. Data are shown as means $\pm \mathrm{SD}$ of 8 animals per group. ${ }^{\mathrm{a}}$ Mean value was significantly different from that of normal control rats. ${ }^{b}$ Mean value was significantly different between group 2 and groups 3, 4, 5 and 6 .

According to the data shown in Table 2, significant decreases in the levels of serum total protein $(P<0.05)$ and glucose $(P<0.05)$, and statistically enhancement in the levels of serum triglycerides $(\mathrm{P}$ $<0.001)$ and cholesterol $(P<0.000)$ were detected in rats exposed to only malathion (group 2$)$. The level of serum total protein was remarkable decreased $(P<0.05)$ and the level of cholesterol was increased $(P<0.05)$, while the levels glucose and triglycerides were unchanged in rats subjected to canola oil plus malathion. In comparison with normal control rats of group 1, the levels of total 
protein, glucose, triglycerides and cholesterol were statistically unchanged in rats treated with sesame oil plus malathion (group 3), sesame oil (group 5) and canola oil (group 6).

Statistically, the treatment of rats with only malathion (group 2) showed increases on the level of serum creatinine $(P<0.000)$ and uric acid $(P<0.001)$, while these parameters were significantly unchanged in the rats of groups 3, 4, 5 and 6 as compared with control rats (Table 3). Noticeably increases of serum MDA were observed in rats treated with malathion $(P<0.000)$, sesame oil plus malathion $(P<0.05)$, canola oil plus malathion $(P<0.001)$. Significant decreases in the level of serum CAT were observed in rats treated with malathion $(P<0.000)$, sesame oil plus malathion $(P<$ $0.05)$, canola oil plus malathion $(P<0.001)$. In comparison with control rats, there were no significant alterations were noted in the levels of serum creatinine, uric acid, MDA and CAT in normal rats treated with sesame oil (group 5) and canola oil (group 6) (Table 3).

Table 1: Serum ALT, AST, ALP and total bilirubin levels in control (group 1), malathion (group 2), sesame oil plus malathion (group 3), canola oil plus malathion (group 4), sesame oil (group 5) and canola oil (group 6) treated rats after eight weeks.

\begin{tabular}{ccccc}
\hline Parameters & $\begin{array}{c}\text { ALT } \\
(\mathbf{U} / \mathbf{L})\end{array}$ & $\begin{array}{c}\text { AST } \\
(\mathbf{U} / \mathbf{L})\end{array}$ & $\begin{array}{c}\text { ALP } \\
(\mathbf{U} / \mathbf{L})\end{array}$ & $\begin{array}{c}\text { Total bilirubin } \\
(\boldsymbol{\mu m o l} / \mathbf{L})\end{array}$ \\
\hline Groups & $55.20 \pm 8.11$ & $95.22 \pm 7.42$ & $177.11 \pm 12.33$ & $2.12 \pm 0.55$ \\
Group 1 & $99.31 \pm 12.61^{\mathrm{ab}}$ & $154.43 \pm 11.60^{\mathrm{ab}}$ & $266.88 \pm 13.12^{\mathrm{ab}}$ & $7.34 \pm 1.08^{\mathrm{ab}}$ \\
Group 3 & $66.70 \pm 8.81^{\mathrm{a}}$ & $112.44 \pm 6.76^{\mathrm{a}}$ & $201.66 \pm 10.98^{\mathrm{a}}$ & $3.33 \pm 0.95^{\mathrm{a}}$ \\
Group 4 & $78.65 \pm 7.74^{\mathrm{a}}$ & $133.60 \pm 7.48^{\mathrm{a}}$ & $233.51 \pm 9.78^{\mathrm{a}}$ & $4.78 \pm 1.10^{\mathrm{a}}$ \\
Group 5 & $53.11 \pm 7.54$ & $98.47 \pm 6.91$ & $175.33 \pm 9.90$ & $2.09 \pm 0.43$ \\
Group 6 & $54.23 \pm 6.11$ & $92.31 \pm 10.70$ & $180.55 \pm 7.66$ & $2.14 \pm 0.41$ \\
\hline
\end{tabular}

Data are shown as means \pm SD of 8 animals per group. ${ }^{a}$ Mean value was significantly different from that of normal control rats. ${ }^{b}$ Mean value was significantly different between group 2 and groups 3, 4, 5 and 6 .

Table 2: Serum total protein, glucose, triglycerides and cholesterol levels in control (group 1), malathion (group 2), sesame oil plus malathion (group 3), canola oil plus malathion (group 4), sesame oil (group 5) and canola oil (group 6) treated rats after eight weeks.

\begin{tabular}{ccccc}
\hline Parameters & $\begin{array}{c}\text { Total protein } \\
\mathbf{( g / L )}\end{array}$ & $\begin{array}{c}\text { Glucose } \\
\mathbf{( m m o l} / \mathbf{L})\end{array}$ & $\begin{array}{c}\text { Triglycerides } \\
(\mathbf{m m o l} / \mathbf{L})\end{array}$ & $\begin{array}{c}\text { Chloesterol } \\
(\mathbf{m m o l} / \mathbf{L})\end{array}$ \\
\hline Groups & $58.44 \pm 3.21$ & $4.81 \pm 0.88$ & $0.53 \pm 0.08$ & $1.11 \pm 0.10$ \\
Group 1 & $49.88 \pm 4.93^{\mathrm{ab}}$ & $3.76 \pm 0.67^{\mathrm{ab}}$ & $1.17 \pm 0.23^{\mathrm{ab}}$ & $2.33 \pm 0.45^{\mathrm{ab}}$ \\
Group 3 & $59.11 \pm 4.22$ & $5.01 \pm 0.58$ & $0.50 \pm 0.03$ & $1.01 \pm 0.20$ \\
Group 4 & $51.11 \pm 2.13$ & $4.71 \pm 0.54$ & $0.58 \pm 0.11$ & $1.45 \pm 0.30^{\mathrm{a}}$ \\
Group 5 & $59.66 \pm 2.48$ & $4.92 \pm .41$ & $0.51 \pm 0.04$ & $1.08 \pm 0.09$ \\
Group 6 & $60.11 \pm 3.17$ & $5.14 \pm 0.78$ & $0.49 \pm 0.10$ & $1.014 \pm 0.12$ \\
\hline
\end{tabular}

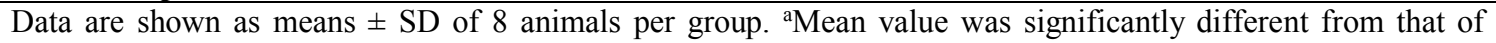
normal control rats. ${ }^{b}$ Mean value was significantly different between group 2 and groups 3, 4, 5 and 6 .

Table 3: Serum creatinine, uric acid, MDA and CAT levels in control (group 1), malathion (group 2), sesame oil plus malathion (group 3), canola oil plus malathion (group 4), sesame oil (group 5) and canola oil (group 6) treated rats after eight weeks.

\begin{tabular}{lcccc}
\hline \multicolumn{1}{c}{ Parameters } & $\begin{array}{c}\text { Creatinine } \\
(\boldsymbol{\mu m o l} / \mathbf{L})\end{array}$ & $\begin{array}{c}\text { Uric acid } \\
(\boldsymbol{\mu m o l} / \mathbf{L})\end{array}$ & $\begin{array}{c}\text { MDA } \\
(\mathbf{n m o l} / \mathbf{m l})\end{array}$ & $\begin{array}{c}\text { CAT } \\
(\mathbf{U} / \mathbf{m l})\end{array}$ \\
\hline Groups & $31.22 \pm 1.87$ & $66.14 \pm 3.51$ & $14.37 \pm 1.54$ & $2.15 \pm 0.16$ \\
Group 1 & $55.66 \pm 3.95^{\mathrm{ab}}$ & $93.07 \pm 6.61^{\mathrm{ab}}$ & $27.42 \pm 5.12^{\mathrm{ab}}$ & $1.35 \pm 0.08^{\mathrm{ab}}$ \\
Group 3 & $30.83 \pm 2.08$ & $65.71 \pm 4.11$ & $18.11 \pm 2.78^{\mathrm{a}}$ & $1.76 \pm 0.03^{\mathrm{a}}$ \\
Group 4 & $33.22 \pm 3.41$ & $80.24 \pm 3.97$ & $21.70 \pm 4.65^{\mathrm{a}}$ & $1.54 \pm 0.05^{\mathrm{a}}$ \\
Group 5 & $30.44 \pm 2.47$ & $62.77 \pm 5.10$ & $13.77 \pm 1.21$ & $2.21 \pm 0.12$ \\
Group 6 & $32.55 \pm 2.91$ & $67.83 \pm 4.79$ & $15.06 \pm 1.80$ & $2.17 \pm 0.18$ \\
\hline
\end{tabular}

Data are shown as means \pm SD of 8 animals per group. ${ }^{a}$ Mean value was significantly different from that of normal control rats. ${ }^{b}$ Mean value was significantly different between group 2 and groups $3,4,5$ and 6 


\section{Discussion}

Pesticides are among the most extensively used chemicals in the world today and they are also among the most hazardous compounds to the human being as well. As pesticides are toxic by nature, they are also potentially hazardous to human, animals, other organisms as well as the environment. A report from World Health Organization (WHO) indicated that over 200,000 people are killed due to the toxicity of these dangerous chemicals every year. Although pesticides are intended to harm only the target pest, if not used correctly, they can also harm to the people or the environment. Pesticide intoxication may be caused either by swallowing accidently, or by inhalation of fumes or by skin contact or accidental eye exposure (Dawson et al., 2010; Lee et al., 2011; Mostafalou and Abdollahi, 2012; Makris et al., 2019). Medicinal plants have been the basis for medicinal treatment through much of human history, and such traditional medicines are still widely practiced today where many people across the world are resorting to these products for treatment of various health challenges in different healthcare settings (Begaa and Messaoudi, 2019).

The present study showed that malathion induced a significant reduction of body weight gain. This result is in agreement with previous studies who demonstrated morphologic and symptomatic modifications in morphometric parameters following exposure to malathion. These changes were characteristic of acetylcholinesterase inhibition including accumulation of acetylcholine and subsequent activation of cholinergic, muscarinic and nicotinic receptors as well as the neurological deficits in experimental animals exposed to malathion (Campana et al., 2008). All these disturbances can lead to various toxic effects in animals, including their feeding ability, and therefore, their metabolisms performances (Farag et al., 2000). Moreover, the reduction of body weight may be attributed to the effect of insecticides on gastrointestinal tract resulting in decreased appetite and absorption of nutrients from gut or might due direct toxicity (Venkateshwarlu et al., 1997; Sankar et al., 2012).

The present study showed that the exposure of rats to malathion caused extensive changes in hematological and biochemical parameters. The obtained data showed that the exposure to malathion caused highly decrease in RBC and WBC counts, and $\mathrm{Hb}$ and Hct values. Hematological characteristics have been widely used in the diagnosis of variety of diseases and pathologies induced by different toxicant including pesticides. Previous studies showed that RBC and WBC counts, and $\mathrm{Hb}$ and Hct values were significantly decreased in experimental rats exposed to malathion and different pesticides (Moallem et al., 2014; Aroonvilairat et al., 2018; Kasmi et al., 2018; Mohi El-Din et al., 2018; Khalifa and Alkhalf, 2019). Shakoori et al. (1990) suggested that the decrease in RBC count is either indicative of excessive damage to erythrocytes or inhibition of erythrocyte formation. Reduction in $\mathrm{Hb}$ concentration may be due to increased rate of breakdown of red cells and/or reduction in the rate of $\mathrm{RBC}$ formation. The present decrease in Hct is attributable to the reduction in $\mathrm{RBC}$ count caused either destruction or reduction in size. Decreased WBC was probably due to harmful effects of malathion on bone marrow and hematopoietic organs. Low WBC count (Leukopenia) is usually caused by bone marrow problems especially when exposed to certain chemicals like pesticides which can hurt the bone marrow's ability to make WBC (Okonkwo et al., 2019).

Serum ALT, AST, ALP, and total bilirubin are useful biomarkers of liver injury. Scientific reports confirm that, when liver tissues are injured, additional of these parameters were released into the bloodstream and raise their levels. As a result, the amount of these parameters in the blood is directly associated with the amount of liver injured. The results reported in this study are in agreement with previous studies, which indicated that exposure to malathion and other pesticides induced severe adverse biochemical alterations that affect the functional and structural integrity of the liver tissues in experimental animals (Al-Attar, 2010; Al-Attar, 2015; Kasmi et al., 2018; Selmi et al., 2018; Aboubakr et al., 2019; Jalili et al., 2019; Khalifa and Alkhalf, 2019).

The present results revealed that the exposure to malathion led to the decline of serum total protein level, while the levels of serum glucose, triglycerides and cholesterol were significantly enhanced. These results are consistent with previous studies which indicated that exposure to malathion and other pesticides induced severe disturbance of proteins, carbohydrates and lipids metabolism (Al-Attar, 2015; El-Beih et al., 2017; Selmi et al., 2018; Khalifa and Alkhalf, 2019). The decline of serum total protein indicates the presence of para proteins or decreased antibody production. Moreover, this change of serum total protein level may be due an alternation in the 
intracellular protein synthesis mechanism and the level of oxidative enzymes in liver. The increase of serum glucose might have been due to the lesser availability of insulin and an inhibition of glycogenolysis and stimulating gluconeogenesis in liver (Petersen et al., 2017). The present hyperlipidemia may be attributed to the stimulation of catecholamines, which stimulate lipolysis and increase fatty acid production. The elevation in total serum triglycerides and cholesterol levels that observed in present investigation could be due to blockage of liver bile ducts causing reduction or cessation of its secretion to the duodenum subsequently causing cholestasis. Furthermore, this could be attributed to increased hepatic synthesis and/or diminished hepatic degradation of lipids due to reduced lipoprotein lipase activity (Hassan et al., 2010; Kalender et al., 2010).

The present study evaluated the kidney function by measuring the levels of serum creatinine and uric acid. These parameters were significantly increased in rats exposed to malathion. The kidney is one of the target organs of experimental animals attacked by pesticides (Al-Attar, 2010; Mansour and Mossa, 2010; Karimani et al., 2019). A disorder of kidney function reduces excretion of creatinine, resulting in increased blood creatinine levels. Thus, creatinine levels give an approximation of the glomerular filtration rate. However, it is known that increase of creatinine occurred with renal failure (Hayes, 1994). Previous investigations showed a significant enhancement of blood creatinine, urea and uric acid levels, and renal histological changes in experimental animals exposed to malathion and other pesticides (Al-Attar, 2015; Baiomy et al., 2015; Kanbur et al., 2016; Li et al., 2016; Kaya et al., 2018; Muhammad et al., 2019).

The present study showed that malathion induced oxidative stress which confirmed by the increase of serum MDA level and the decrease of CAT level. These findings are generally in agreement with previous experimental investigations on animals exposed to malathion and other pesticides (Avci et al., 2018; Selmi et al., 2018; Uchendu et al., 2018; Aboubakr et al., 2019; Jalili et al., 2019; Khalifa Alkhalf, 2019). MDA is an end product of lipid peroxidation, and therefore increased concentrations indicate an increase in reactive oxygen species (ROS) concentration and resulting oxidative damage. The enzyme CAT catalyzes the decomposition of $\mathrm{H}_{2} \mathrm{O}_{2}$ to the much less reactive products oxygen and water. It is a highly conserved enzyme found in nearly all living organisms that are exposed to oxygen. CAT is also an incredibly effective enzyme, having one of the highest turnover numbers known. CAT neutralizes ROS and is therefore considered to be antioxidant enzymes. Cellular antioxidant defense system consists of enzymes such as CAT, superoxide dismutase (SOD), glutathione peroxidase (GPx) and glutathione-S-transferase (GST) and nonenzymatic antioxidants such as MDA. These endogenous antioxidants play an essential role in the direct elimination of free radicals including reactive oxygen and nitrogen species (RONS) which are known to induce oxidative injury in biological components (Sánchez-Valle et al., 2012; Li et al., 2015). Multiple studies provide evidence of the tendency of pesticides to disturb oxidative balance, which leads to oxidative stress. When an imbalance between free radical production and detoxification occurs, RONS production may overwhelm antioxidant defenses, leading to the generation of a noxious condition called oxidative stress and overall to the impairment of the cellular functions. This phenomenon is observed in many pathological cases. The balance between the production of free radicals and antioxidant defenses in the body has important health implications: if there are too many free radicals or too few antioxidants for protection, a condition of oxidative stress develops, which may cause chronic and permanent damage (Harman, 1999; Grimm et al., 2016; Liguori et al., 2018).

The present results of this study indicated that sesame oil and canola oil given orally attenuated the extensive alterations in hematological and biochemical parameters in malathion intoxicated male rats. Furthermore, the antioxidant activities of sesame oil and canola oil were confirmed by the present evaluations of oxidative stress markers in rats subjected to malathion toxicity. The protective effects of sesame oil against several chemical toxicants associated with inhibition of the oxidative stress in experimental animals were reported by previous investigations (Liu et al., 2015; Soliman et al., 2015, Al-Attar et al., 2017; 2018). Al-Attar et al. (2017; 2018) showed that the sesame oil attenuated the physiological disturbances and histopathological alterations induced by diazinon intoxication in male rats. Moreover, the antioxidant properties of sesame oil support the bioactive role of its protective effects on diazinon toxicity. They suggested that sesame oil could be used as preventive factors against the toxicity of diazinon due to its antioxidant properties. Papazzo et al. (2011) showed that canola oil ingestion mediated life span shortening of stroke-prone spontaneously 
hypertensive (SHRSP) rats leads to changes in oxidative status. The plasma lipids were reduced after canola oil ingestion highlighting the health benefits of canola oil intake. Despite the improvement in the plasma lipids, canola oil was detrimental to the SHRSP rat as their life span is reduced. Han et al. (2017) investigated the effects of canolol (a phenolic compound isolated from crude canola oil) on hydrogen peroxide $\left(\mathrm{H}_{2} \mathrm{O}_{2}\right)$-induced oxidative stress in AGS cells. The pretreatment of AGS cells by canolol resulted in a reduction in ROS and MDA levels. They concluded that canolol effectively protected AGS cells against $\mathrm{H}_{2} \mathrm{O}_{2}$-induced oxidative stress and its antioxidative effect was significant. Kumar et al. (2019) reported that canola oil exerted protective effect against $\mathrm{AlCl}_{3}$-induced neuronal damage, marked by improved spatial memory and improved brain antioxidant status. Canola oil treatment also exerted protective effects toward CAT levels in both hippocampus and frontal cortex. However, it can not excluded that the possibility that sesame oil and canola oil offer protection against ROS-mediated damage by enhancing cellular antioxidant defense and reducing severe hematological and biochemical changes in male rats treated with malathion. From the results of the present study, it can be concluded that sesame oil and canola oil could be used as safe potential natural products in the treatment of malathion toxicity due to their antioxidant properties. Collectively, the most protective effects were observed in rats treated with sesame oil followed by canola oil. Additionally, further hematological and biochemical studies will be required to investigate the effects of different concentrations and doses of sesame oil and canola oil against malathion toxicity.

\section{References}

Abdel-Salam, O.M.E., A.F. Galal, M.M. Hassanane, L.M. Salem, S.A Nada and F.A. Morsy, 2018. Grape seed extract alone or combined with atropine in treatment of malathion induced neuroand genotoxicity. J. Nanosci. Nanotechnol., 18: 564-575.

Aboubakr, H.M., E.A. Elzohairy, A.A. Ali, L.A. Rashed, N.K. Elkady and A.S.A. Soliman, 2019. Therapeutic effects of $N$-acetylcysteine against malathion-induced hepatotoxicity. Egypt. J. Forensic Sci., 9: 34.

Ackman, R.G., 1994. Canola Fatty Acids-An Ideal Mixture for Health, Nutrition and Food Use. In: Canola and Rapeseed: Production, Chemistry, Nutrition and Processing Technology. Shahidi F. (Ed.), Van Nostrand Reinhold, New York, pp. 81-89.

Aebi, H., 1984. Catalase in vitro. Methods Enzymol., 105:121-126.

Al-Attar, A.M., 2010. Physiological and histopathological investigations on the effects of $\alpha$-lipoic acid in rats exposed to malathion. J. Biomed. Biotechnol., 2010: 1-8.

Al-Attar, A.M., 2015. Effect of grapeseed oil on diazinon-induced physiological and histopathological alterations in rats. Saudi J. Biol. Sci., 22: 284-292.

Al-Attar, A.M., M.H.R Elnaggar and E.A. Almalki, 2017. Protective effect of some plant oils on diazinon induced hepatorenal toxicity in male rats. Saudi J. Biol. Sci., 24: 1162-1171.

Al-Attar, A.M., M.H.R Elnaggar and E.A. Almalki, 2018. Physiological study on the influence of some plant oils in rats exposed to a sublethal concentration of diazinon. Saudi J. Biol. Sci., 25: 786-796.

Aroonvilairat S., C. Tangjarukij, T., Sornprachum P. Chaisuriya, T. Siwadune and K. Ratanabanangkoon, 2018. Effects of topical exposure to a mixture of chlorpyrifos, cypermethrin and captan on the hematological and immunological systems in male Wistar rats. Environ. Toxicol. Pharmacol., 59: 53-60.

Avci, B., S.S. Bilge, G. Arslan, O. Alici, O. Darakci, T. Baratzada, E. Ciftcioglu, T. Yardan and A. Bozkurt, 2018. Protective effects of dietary omega-3 fatty acid supplementation on organophosphate poisoning. Toxicol. Ind. Health, 34: 69-82.

Baiomy, A.A., H.F. Attia, M.M. Soliman and O. Makrum, 2015. Protective effect of ginger and zinc chloride mixture on the liver and kidney alterations induced by malathion toxicity Int. J. Immunopathol. Pharmacol., 28: 122-128.

Begaa, S. and M. Messaoudi, 2019 Toxicological aspect of some selected medicinal plant samples collected from Djelfa, Algeria Region. Biol. Trace Elem. Res., 187: 301-306.

Campana, A.D., F. Sanchez, C. Gamboa, J. Gomez-Villalobos Mde, F. De La Cruz, S. Zamudio and G. Flores, 2008. Dendritic morphology on neurons from prefrontal cortex hippocampus, and 
nucleus accumbens is altered in adult male mice exposed to repeated low dose of malathion, Synapses, 62: 283-290.

Dawson, A.H., M. Eddleston, L. Senarathna, F. Mohamed, I. Gawarammana, S.J. Bowe, G. Manuweera and N.A. Buckley, 2010. Acute human lethal toxicity of agricultural pesticides: a prospective cohort study. PLoS Medicine, 7: e1000357.

El-Beih, N.M., G. Ramadan, M.A. Khorshed and R.S.A. Ahmed, 2017. Biochemical alterations in insecticides-treated male albino rats: potential modulatory effects of a standardized aged garlic extract. Indian J. Tradit. Know., 16: 181-188.

Farag, A.T., M.H. Ewediah and A.M. El-Okazy, 2000. Reproductive toxicology of acephate in male mice, Reprod. Toxicol., 14: 457-462.

Grimm, A., K. Friedland and A. Eckert, 2016. Mitochondrial dysfunction: the missing link between aging and sporadic Alzheimer's disease. Biogerontology, 17: 281-296.

Gupta, V.K., N.J. Siddiqi, A.K. Ojha and B. Sharma, 2019. Hepatoprotective effect of Aloe vera against cartap- and malathion-induced toxicity in Wistar rats. J. Cell Physiol., 234: 1832918343

Han, L., X. Xia, X. Xiang, F. Huang and Z. Zhang, 2017. Protective effects of canolol against hydrogen peroxide-induced oxidative stress in AGS cells. RSC Adv., 7: 42826-42832.

Hariri, A.T., S.A. Moallem, M. Mahmoudi, B. Memar, B.M. Razavi and H. Hosseinzadeh, 2018. Effect of Crocus sativus L. stigma (saffron) against subacute effect of diazinon: histopathological, hematological, biochemical and genotoxicity evaluations in rats. J. Pharmacopuncture, $21: 61-69$.

Harman, D., 1999. Aging and oxidative stress. JI.FCC., 10: 24-47.

Hassan H.A. and M.I. Yousef, 2010. Ameliorating effect of chicory (Cichorium intybus L.)supplemented diet against nitrosamine precursors-induced liver injury and oxidative stress in male rats. Food Chem. Toxicol., 48: 2163-169.

Hayes, A.W. 1994. Principles and Methods of Toxicology, $3^{\text {rd }}$ Ed, Raven Press New York, pp. 243283.

Hosseini S.A., M. Saidijam, J. Karimi, R. Yadegar Azari, V. Hosseini and A. Ranjbar, 2019. cerium oxide nanoparticle effects on paraoxonase-1 activity and oxidative toxic stress induced by malathion: a potential antioxidant compound, yes or no? Indian J. Clin. Biochem., 34: 336341.

Jalili, C., M.H. Farzaei, S. Roshankhah and M.R. Salahshoor, 2019 Resveratrol attenuates malathioninduced liver damage by reducing oxidative stress. J. Lab. Physicians. 11: 212-219.

Kalender S., F.G. Uzun, D. Durak, F. Demir, and Y. Kalender, 2010. Malathion-induced hepatotoxicity in rats: the effects of vitamins $C$ and E. Food Chem. Toxicol., 48: 633-638.

Kanbur, M., Y., Siliğ G. Eraslan, M., Karabacak Z. Soyer Sarıca and S. Şahin, 2016. The toxic effect of cypermethrin, amitraz and combinations of cypermethrin-amitraz in rats. Environ. Sci. Pollut. Res. Int., 23: 5232-5242.

Kapka-Skrzypczak, L., M. Cyranka, M. Skrzypczak, and M. Kruszewski, 2011. Biomonitoring and biomarkers of organophosphate pesticides exposure - state of the art. Ann. Agric. Environ. Med., 18: 294

Karimani, A., M. Heidarpour and A. Moghaddam Jafari, 2019. Protective effects of glycyrrhizin on sub-chronic diazinon-induced biochemical, hematological alterations and oxidative stress indices in male Wistar rats. Drug Chem. Toxicol., 42: 300-308.

Kasmi, S., I. Bkhairia, B. Harrabi, H. Mnif, R. Marrakchi, H. Ghozzi, C. Kallel, M. Nasri, K. Zeghal, K. Jamoussi and A. Hakim, 2018. Modulatory effects of quercetin on liver histopathological, biochemical, hematological, oxidative stress and DNA alterations in rats exposed to graded doses of score 250. Toxicol. Mech. Methods, 28: 12-22.

Kaya, Y., O. Bas, H. Hanci, S. Cankaya, I., Nalbant E. Odaci, H. Avni Uydu and A. Aslan, 2018. Acute renal involvement in organophosphate poisoning: histological and immunochemical investigations. Ren. Fail., 40: 410-415.

Kennedy, D.A., A. Lupattelli, G. Koren and H. Nordeng, 2016. Safety classification of herbal medicines used in pregnancy in a multinational study. BMC Complement. Altern. Med., 16: 102. 
Khalifa, F.K. and M.I. Alkhalf, 2019. Effects of black seed and thyme leaves dietary supplements against malathion insecticide-induced toxicity in experimental rat model. J. King Saud Univ. Sci., In Press.

Klaasen, C.D., 1990. Nonmetallic environmental toxicants: air pollutants, solvents and vapors, and pesticides. In: The Pharmacological Basis of Therapeutics. Goodman Gilman, A., Rall, T.W., Nies, A.S. and Taylor, P. (Eds.), New York: Pergamon Press Inc., pp.1615-1635.

Konan, A., J. Datte and P. Yapo, 2008. Nitric oxide pathway- mediated relaxant effect of aqueous sesame leaves extract (Sesamum radiatum Schum. \& Thonn.) in the guinea-pig isolated aorta smooth muscle. BMC Complement. Altern. Med., $8: 23$.

Kumar, A., S.B. Mallik, S. Rijal, N. Changdar, J. Mudgal and R.R. Shenoy, 2019. Dietary oils ameliorate aluminum chloride-induced memory deficit in wistar rats. Phacog Mag., 15: 36-42.

Kwong, T.C., 2002. Organophosphate pesticides: biochemistry andclinical toxicology. Ther. Drug Monit., 24: 144-149.

Lee, S.J., L. Mehler, J. Beckman, B. Diebolt-Brown, J. Prado, M. Lackovic, J. Waltz, P. Mulay, A. Schwartz, Y. Mitchell, S. Moraga-McHaley, R. Gergely and G.M. Calvert, 2011. Acute pesticide illnesses associated with off-target pesticide drift from agricultural applications: 11 States, 1998-2006. Environ. Health Perspect., 119: 1162.

Li, S., H.Y. Tan, N. Wang, Z.J. Zhang, L. Lao, C.W. Wong and Y. Feng, 2015. The role of oxidative stress and antioxidants in liver diseases. Int. J. Mol. Sci., 16:26087-26124.

Li, S., C., Cao H. Shi, S. Yang, L. Qi, X. Zhao and C. Sun, 2016. Effect of quercetin against mixture of four organophosphate pesticides induced nephrotoxicity in rats. Xenobiotica, 46: 225-233.

Liguori, I., G. Russo, F. Curcio, G. Bulli, L. Aran, D. Della-Morte, G. Gargiulo, G. Testa, F. Cacciatore, D. Bonaduce and P. Abete, 2018. Oxidative stress, aging, and diseases. Clin. Interv. Aging, 13: 757-772.

Liu, C.T., S.P. Chien, D.Z. Hsu, S. Periasamy and M.Y. Liu, 2015. Curative effect of sesame oil in a rat model of chronic kidney disease. Nephrolo., 20: 922-930.

Lushchak, V.I., T.M. Matviishyn, V.V. Husak, J.M. Storey and K.B. Storey, 2018. Pesticide toxicity: a mechanistic approach. EXCLI J., 17: 1101-1136.

Makris, K.C., C. Konstantinou, X.D. Andrianou, P. Charisiadis, A. Kyriacou, M.O. Gribble and C.A. Christophi, 2019. A cluster-randomized crossover trial of organic diet impact on biomarkers of exposure to pesticides and biomarkers of oxidative stress/inflammation in primary school children. PLoS One, 14: e0219420.

Mamane, A., C. Raherison, J.F. Tessier,.I Baldi and G. Bouvier, 2015. Environmental exposure to pesticides and respiratory health. Eur. Respir. Rev., 24: 462-473.

Mansour, S.A. and A.H. Mossa, 2010. Oxidative damage, biochemical and histopathological alterations in rats exposed to chlorpyrifos and the antioxidant role of zinc. Pestic. Biochem. Physiol., 96: 14-23.

Moallem, S.A., A.T. Hariri, M. Mahmoudi and H. Hosseinzadeh, 2014. Effect of aqueous extract of Crocus sativus L. (saffron) stigma against subacute effect of diazinon on specific biomarkers in rats. Toxicol. Ind. Health, 30: 141-146.

Mohi El-Din, M.M., A.M. Mostafa and A. Abd-Elkader, 2014. Experimental studies on the effect of (Lambda-Cyhalothrin) insecticide on lungs and the ameliorating effect of plant extracts (Ginseng (Panax Ginseng) and garlic (Allium sativum L.) on asthma development in albino rats. BMC Res. Notes, 7: 243.

Mostafalou, S. and M. Abdollahi, 2012. Concerns of environmental persistence of pesticides and human chronic diseases. Clin. Exp. Pharmacol., S5: e002.

Muhammad, Y., E. Nazia, Q.S.U. Rehman, A. Abid, K.W. Ali and K. Azizullah, 2019. Effect of organophosphate pesticide (chlorpyrifos, fipronil, and malathion) on certain organs of Rattus rattus. GSC Biol Pharm. Sci., 06: 011-015.

Naczk, M., R. Amarowicz, A. Sullivan and F. Shahidi, 1998. Current research developments on polyphenolics of rapeseed/canola: A Review. Food Chem., 62: 489-502.

Ohkawa, H., W. Ohishi and K. Yagi, 1979. Assay for lipid peroxides in animal tissues by thiobarbituric acid reaction. Anal Biochem., 95: 351-358. 
Okonkwo, C.O., O.C. Ohaeri and I.J. Atangwho, 2019. Haematological changes in rats exposed to insecticidal oils from the leaves of Cassia occidentalis and Euphorbia milii. Heliyon, 5: $\mathrm{e} 01746$.

Papazzo, A., X.A. Conlan, L. Lexis and P.A. Lewandowski, 2011. Differential effects of dietary canola and soybean oil intake on oxidative stress in stroke-prone spontaneously hypertensive rats. Lipids Health Dis., 10: 98.

Paul, K.C., C. Ling, A. Lee, T.M. To, M. Cockburn, M. Haan and B. Ritz, 2018. Cognitive decline, mortality, and organophosphorus exposure in aging Mexican Americans. Environ. Res., 160: 132-139.

Petersen, M.C., D.F. Vatner and GI. Shulman, 2017. Regulation of hepatic glucose metabolism in health and disease. Nat. Rev. Endocrinol., 13: 572-587.

Rice, R., 1994. Mediterranean Diet. Lancet, 344: 893-894.

Sánchez-Valle, V., N.C. Chávez-Tapia, M. Uribe and N. Méndez-Sánchez, 2012. Role of oxidative stress and molecular changes in liver fibrosis: a review. Curr. Med. Chem., 19: 4850-4860.

Sankar, D., G. Sambandam, M. Ramakrishna Rao and K.V. Pugalendi, 2005. Modulation of blood pressure, lipid profiles and redox status in hypertensive patients taking different edible oils. Clin. Chim., 355: 97-104.

Sankar, P., A.G. Telang and A. Manimaran, 2012. Protective effect of curcumin on cypermethrininduced oxidative stress in Wistar rats. Exp. Toxicol. Pathol., 64: 487-493.

Selmi, S., K. Rtibi, D. Grami, H. Sebai and L. Marzouki, 2018. Malathion, an organophosphate insecticide, provokes metabolic, histopathologic and molecular disorders in liver and kidney in prepubertal male mice. Toxicol. Rep., 5: 189-195.

Shakoori, A.R., F. Aziz, J. Alam and S.S., Ali, 1990. Toxic effects of Talstar, a new synthetic pyrethroid, on blood and liver of rabbits. Pak. J. Zool., 22: 289-300.

Shittu, L., R.K. Shittu, O. Olufemi, A.O. Tayo and A.A.A. Osunubi, 2009. Hypoglycaemia and improved testicular parameters in Sesamum radiatum treated normo-glycaemic adult male Sprague Dawley rats. Afr. J. Biotechnol., 8: 2878-2886.

Soliman, M.M., H.F. Attia and G.A. El-Ella, 2015. Genetic and histopathological alterations induced by cypermethrin in rat kidney and liver: Protection by sesame oil. Int. J. Immunopathol. Pharmacol., 28: 508-520.

Taylor, P., 1990. Anticholinesterase agents. In: The Pharmacological Basis of Therapeutics. Goodman. Gilman, A., T.W. Rall, A.S. Nies and P. Taylor (Eds.), New York: Pergamon Press Inc., pp. 131-147.

Uchendu, C., S.F. Ambali, J.O. Ayo and K.A.N. Esievo, 2018. Chronic co-exposure to chlorpyrifos and deltamethrin pesticides induces alterations in serum lipids and oxidative stress in Wistar rats: mitigating role of alpha-lipoic acid. Environ. Sci. Pollut. Res. Int., 25: 19605-19611.

United States Environmental Protection Agency (U.S. EPA)., 2006. Reregistration Eligibility Decision (RED) for malathion; EPA 738-R-06-030; U.S. Environmental Protection Agency, Office of Prevention, Pesticides and Toxic Substances, Office of Pesticide Programs, U.S. Government Printing Office: Washington, DC.

Venkateshwarlu, P., B.J.R. Sharma, B. Kalakumar, K.S. Reddy and P. Ravikumar, 1997. Comparative evaluation of toxicity of carbaryl, cypermethrin and malathion of testis in mice. Indian $\mathrm{J}$. Toxicol., 4: 33-37.

Xu, J., C. Ma, L. Han, H. Gao, Q. Zhou, M. Yang, C. Chen, Q. Deng, Q. Huang and F. Huang, 2014. Optimized rapeseed oils rich in endogenous micronutrients ameliorate risk factors of atherosclerosis in high fat diet fed rats. Lipids Health Dis., 13: 166. 